\title{
Entre lírica y teatro: tradiciones y confluencias genéricas en la «Égloga de Torino»
}

\author{
Alba AGRAZ ORTIZ \\ Universidad de Salamanca \\ alba_ao@usal.es \\ A Javier San José, por sus pacientes revisiones y su \\ entusiasmo eclógico siempre.
}

\section{RESUMEN}

Este trabajo estudia una de las primeras obras pastoriles del teatro castellano, la «Égloga de Torino», incluida en la anónima ficción sentimental Question de amor (Valencia, 1513). Partiendo de su lectura detallada y atendiendo especialmente, por un lado, a su construcción dramática y, por otro, a la retórica empleada, se pretende iluminar la encrucijada literaria y cultural en la que se inserta. El análisis estructural y el examen de los diálogos permiten establecer una red de relaciones con las tradiciones literarias y paraliterarias que están detrás de la obrita (incipiente teatro castellano de estirpe enciniana, poesía de cancionero, sociedad y fiesta cortesana), así como discutir otras y plantear el grado de vinculación con la coetánea égloga dramática italiana.

Palabras clave: égloga, teatro castellano medieval, teatro renacentista, poesía de cancionero, fasto cortesano.

\begin{abstract}
This paper is an analysis of «Égloga de Torino,» one of the first Castilian pastoral dramas, which is included in the anonymous novel Question de Amor (Valencia, 1513). Starting with a close reading, and paying special attention to its dramatic structure on the one hand, and to its rhetoric on the other one, we will try to shed some light on the literary and cultural crossroads to which the eclogue belongs. The analysis of both the structure and the dialogue will allow us to establish a link with the literary and paraliterary traditions on which the eclogue stands (the nascent Castilian theatre of Encinian roots, court poetry, pageantry and court entertainment), and also to discuss other works and to study the possible connection with the contemporary tradition of dramatic Italian eclogue.
\end{abstract}


Key words: Eclogue, Castilian Medieval Theater, Renaissance Theater, Court Poetry, Pageantry.

Junto a las tradiciones populares y religiosas, las cortes de la última Edad Media son, también en Europa, el gran catalizador de las prácticas escénicas del Quinientos. El progresivo desarrollo del espectáculo parateatral —momos, mascaradas, alegorías teatralizadas - cristalizará en un teatro autónomo que, sin embargo, todavía en las primeras décadas del s. XVI, se encuentra en gestación y muy ligado aún a la fiesta social de la que nace: «teatro de palacio», en palabras de A. Hermenegildo (1998), cuya creación está fuertemente condicionada por el contexto de recepción ${ }^{1}$. La ficción sentimental Questión de amor (Valencia, 1513) recrea magníficamente este mundo aristocrático de lujo y pompa autocontemplativa; y en su centro inserta, como decantada, una de las primeras piezas dramáticas del teatro español: la famosa Égloga de Torino, de algo más de seiscientos versos ${ }^{2}$.

La obrita es de clara estirpe enciniana y sigue en particular el patrón de la Égloga de Fileno, Zambardo y Cardonio, pieza ya de la etapa italiana del salmantino ${ }^{3}$. Como señala Pérez Priego, esta pieza sirvió de modelo para un subtipo eclógico muy fecundo en los primeros años del s. XVI, desde la temprana Égloga de Breno, ca.1512 hasta la Farsa a manera de tragedia, de 1537, y que ya inserta elementos celestinescos y de comedia latina a través del modelo naharresco ${ }^{4}$. En él, el conflicto se articula en torno a las quejas patéticas de un pastor enamorado (en

\footnotetext{
${ }^{1}$ Para un estudio más detallado de las interrelaciones entre teatro, parateatro y fiesta a finales del s. XV y primeras décadas del XVI, vid. J. P. W. Crawford (1937), pp. 57-80; R. E. Surtz (1979), pp. 67-124 y (1990), pp. 136-146; J. Oleza (1984a [1981]); J. M. Díez Borque (1987) o T. Ferrer Valls (1993), entre otros.

${ }^{2}$ La novela retrata concretamente la corte napolitana en los primeros años del s. XVI, cuando, a partir de 1506, el Reino de Nápoles pasa a ser virreinato aragonés. Los estrechos vínculos que se habían establecido entre el oriente peninsular y la corte napolitana en el s. $\mathrm{XV}$, con Alfonso el Magnánimo, se refuerzan ahora y se evidencian en el hecho mismo de que una obrita como Questión de amor, que esconde en la ficción la realidad de la corte italiana, se publica precisamente en Valencia (1513). A propósito de ello, señala Ferrer Valls: «La cultura que se elabora en Valencia a principios de siglo es reflejo de la situación de una corte que debió mantener círculos cortesanos internacionales, con doble sede», (1993), pp. 20-21. Para la cultura cortesana del Quinientos valenciano, especialmente potente durante el virreinato de Germana de Foix y su esposo, el duque de Calabria (15261536), vid. J. Oleza (1984b y 1986), J. L. Sirera (1984 y 1986) y T. Ferrer Valls (2007).

${ }^{3} \mathrm{La}$ Égloga de los tres pastores de Encina aparece publicada por primera vez en la edición del Cancionero de 1509 y está inspirada, a su vez, en la segunda égloga del italiano Antonio Tebaldeo: Égloga de Tirsi e Damone; J. P. W. Crawford (1937), pp. 21-22.

${ }^{4}$ M. A. Pérez Priego (2000), pp. 84-86; R. Rodrigo Mancho (1984).
} 
nuestro caso, Torino), sus insinuaciones suicidas, las confidencias al pastor zafio (aquí, Guillardo) como contrapunto cómico y de tensión teatral y, por último, un desenlace que, pese a la orientación trágica, se resuelve en final feliz ${ }^{5}$.

La Égloga de Torino se muestra especial respecto a estas obras (y a otras piezas dramáticas) precisamente en su condición no autónoma, incrustada dentro de un texto literario mayor con el que establece un diálogo. Questión de amor, como digo, sigue las coordenadas de la ficción sentimental, muy cultivada en la última Edad Media castellana y primer Renacimiento. Pero, además, la Questión es perfecto ejemplo de la llamada «novela en clave», como el propio autor explicita al final («Aquí da razón el autor delo pasado y declara la ficion de aquello»): se trata de un juego cortesano en el que la literatura cumple un papel prioritariamente social y lúdico, y, a la vez que retrata a una sociedad (la corte napolitana del 1500), participa como un componente más en el repertorio de diversiones aristocráticas: danzas, banquetes, caza y exhibiciones públicas van de la mano de motes e invenciones, momos y mascaradas, veladas de recitación poética y musical ${ }^{6}$. Unos y otros

${ }^{5}$ El final feliz es reorientación del desenlace trágico (aun en su sarcasmo) del modelo enciniano, que acaba con el suicidio de Fileno. A su vez, este final parte de la tradición italiana coetánea en la que directamente se inspira Encina: Egloga di Favia, de Fileno Gallo y, particularmente, la ya citada Egloga de Tirsi e Damone, de Tebaldeo; Pérez Priego (2002), p. 82 .

${ }^{6}$ El autor de Questión de Amor describe detalladamente la jornada festiva en la que se inserta la representación teatral (C. Perugini, 1995, pp. 98-121). Se comienza con un ostentoso juego de cañas en el que se enfrentan Flamiano y el cardenal, ambos con sus caballeros: «Saliendo todos como en tal fiesta se suele salir, a un llano entre la villa y el mar, donde un grande tablado con mucha tapicería todas las damas estaban, començaron entre ellos mismos el juego de cañas» (C. Perugini, 1995, p. 100). Las fiestas ecuestres (juegos de cañas, torneos y justas, pasos de armas...) fueron muy populares en las cortes de la última Edad Media, donde pasan de ser un ejercicio de preparación bélica en sus orígenes a un entretenimiento aristocrático de carácter espectacular y parateatral; el carácter performativo que había adquirido en los albores del XVI se evidencia en los detalles que la novela da sobre el escenario y acondicionamiento para espectadores, así como el despliegue de vestuario, con el uso abundante de la alegoría a través de las invenciones y la simbología de los colores. Finalizado el simulacro de combate y «siendo tarde» (C. Perugini, 1995, p. 100), se celebra una colación seguida de baile, «que duró hasta la cena» (C. Perugini, 1995, p. 100). El banquete nocturno tiene lugar en un «muy largo y ancho corredor», donde se dispone una «tabla muy larga». De nuevo le sigue un baile en el que participan todos los cortesanos y es entonces cuando tiene lugar la representación teatral que Flamiano ha preparado, con otros cuatro caballeros, para aquella noche. Acabada la égloga, la fiesta continúa con un momo (Flamiano se retira y regresa con el cardenal de Brujas, «vestidos de máscaras») que abre, de nuevo, el baile de máscaras como fin de la jornada festiva. Todos estos festejos remiten al fasto cortesano medieval y son muy similares a los descritos en la Crónica del Condestable don Miguel Lucas de Iranzo, del s. XV (J. de Mata Carriazo, 1940). Sobre el fasto cortesano medieval en la Península puede verse C. Aubrun (1939 y 1942), E. 
elementos se interrelacionan y apelan entre sí como parte de un todo global. Desde esta perspectiva, la Égloga de Torino adquiere un estatus metateatral o metaliterario de tres niveles: I. La ficción autónoma de la égloga: lamentaciones de Torino en su amor por Benita; II. La equivalencia con los personajes de la novela, que son los encargados de escenificar el conflicto amoroso con el disfraz pastoril: TorinoFlamiano, Benita-Belisena, Quiral-Vasquirán (parcialmente, pues el personaje novelístico no es el actor); III. La equivalencia con las personas reales de la corte a través de la novelización en clave (Torino-Flamiano-Ettore Pignatelli?, BenitaBelisena-Bona Sforza, Quiral-Vasquirán- Vázquez?) ${ }^{7}$. Es difícil saber si, en este juego de espejos, el autor transcribe aquí una obra verdaderamente representada en la corte real ${ }^{8} \mathrm{y}$, en tal caso, si fue su autor el mismo que el anónimo de la Questión, si este transcribe un texto ajeno o si tal transcripción parte, no de un texto, sino de una representación vista. La otra opción es que la Égloga sea producto de un ensayo literario más, una incursión del poeta en un género de moda, tal y como hace a lo largo de la novela desde los ejercicios líricos o las exposiciones tratadísticas de debate amoroso. De ser así, la obra indudablemente proyectaría una futura escenificación, a juzgar por las detalladas didascalias (especialmente en el argumento inicial, que construye visual y técnicamente la escena); a la vez, se superpondría a la potencialidad teatral que ya posee la propia novela en clave.

Planteada la naturaleza compleja de la obra (Égloga de Torino), quiero hacer ahora un análisis pormenorizado desde su representatividad, tanto del temprano género dramático de la égloga en España, como de la tradición cancioneril del s. $\mathrm{XV}$, reabsorbida en la forma teatral. Si el primero está presente en la comicidad rústica y la estructura accional a partir del modelo de Encina (e indirectamente, de modelos italianos) que Oleza denomina «modelo bucólico»" ${ }^{9}$, la lírica de Cancionero

Asensio (1958), N. D. Shergold (1967), pp. 113-142; R. E. Surtz (1979), pp. 67-74; M. García (1987) o V. Blay Manzanera (1997). Respecto al siglo XVI y XVII, vid. T. Ferrer Valls (1991), F. Bouza (2000), P. M. Cátedra (2000, 2005) y, en general, el volumen colectivo editado por F. Villaverde (2000). Para el contexto europeo, vid. R. C. Strong (1988), P. Béhar (1999), H. Watanabe-O’Kelly (2000) y J. R. Mulryne (2002, 2004), entre otros.

${ }^{7}$ Las identificaciones, propuestas por B. Croce (1917), pp. 45-53, no son seguras y, de cualquier forma, no tienen relevancia para lo que me interesa. Un completo resumen de las hipótesis planteadas por la crítica puede encontrarse en la introducción de C. Perugini a la novela (1995), pp. 22-28, y, más sistematizadamente, en el cuadro que ofrece F. Vigier (2006), pp. 431-446, como apéndice a su edición. Las implicaciones de estos niveles metaficcionales en la recepción de la obra han sido estudiadas por R. Rohland de Langhehn (1992).

${ }^{8}$ Así lo sugiere J. Oleza (1986), p. 195, siguiendo a J. P. W. Crawford (1937), p. 70.

${ }^{9}$ (1984c), pp. 193 y ss. 
y su universo de tópicos constituye el núcleo retórico y temático de la Égloga, que en muchas ocasiones parece un adiestramiento en el género de las preguntas y respuestas medieval ${ }^{10}$.

En primer lugar, el texto se inscribe conscientemente en la órbita de lo dramático desde la propia disposición textual —el estilo directo, en el que cada parlamento está precedido de la inicial del nombre del personaje que interviene ${ }^{11}$ y, sobre todo, desde los paratextos preliminares según la naciente tradición fijada con el Cancionero de 1496 de Juan del Encina. La égloga en sí misma está previamente encabezada por un amplio argumento (denominado aquí «Introducción») que incorpora el resumen argumental a través de un discurso didascálico; este incluye dramatis personae (los personajes presentados por su nombre y definidos como pastores, e incluso identificados con el actor en la ficción: Torino-Flamiano, Quiral-Marqués de Carliner, Benita-Belisena, Yllana-Ysiana), indicaciones proxémicas (entradas y salidas de los personajes), quinésicas y enunciativas (gestualidad y forma entonativa), y también icónicas, con la mención del laúd como elemento de atrezo y de la ambientación escenográfica («y acostado debaxo de un pino que allí hazen traer», p. 101) ${ }^{12}$.

La introducción, además, incluye la referencia explícita al elemento musical, determinante en el teatro renacentista ${ }^{13}$. En este caso, se trata de dos composiciones líricas con función estructural: una canción de apertura (cantada por Torino y acompañada de laúd, según especifica el argumento: «Entra primero Torino y [...] con un laúd tañe y canta esta canción que al principio de la égloga está», p. 101) y un villancico de cierre, también referido en el argumento («acaban todos tres con un villancico cantando», p.101). Concluido el texto dramático, una acotación expresa marca el villancico anunciado y se añade un segundo atribuido a Guillardo y Torino (que no se prevé en la introducción).

\footnotetext{
${ }^{10}$ Esta última dimensión es, por otro lado, la que nutre también toda la obra de Questión de amor desde el género de la novela sentimental, con el modelo de la Cárcel de amor de San Pedro.

${ }^{11}$ Esta puesta en página, que reproduce C. Perugini (1995) siguiendo la edición de 1513, es la misma que la de las sucesivas ediciones que he podido consultar: Salamanca (1528, fols. XVIII-XIX), Venezia (1554, pp. 48-60) y Amberes (1576, pp. 103-128).

${ }^{12}$ Sigo, para la descripción de didascalias, la clasificación de A. Hermenegildo (2001).

En cuanto al texto de la égloga, aunque se han publicado recientemente dos nuevas ediciones de Question de amor —F. Vigier (2006), P. Andrachuck (2006)—, citaré por la edición de C. Perugini (1995) por serme de más fácil acceso. Las lecturas corregidas que Andrachuk hace a esta las he señalado en nota cuando ha sido pertinente para el desarrollo de mi estudio. Para los paratextos (argumento, canción inicial, villancicos finales) citaré el número de página en la edición de C. Perugini (1995); para el texto propiamente teatral, daré únicamente el número de verso.
}

${ }^{13}$ Vid. J. Subirá (1930), D. Bécker (1993), A. Torrente (2003). 
Estos tres poemas son representativos de la poesía de Cancionero, que no solo en la Égloga de Torino, sino en el propio género eclógico del momento tiene una presencia destacada. La primera es una típica canción cortesana de base zejelesca con retronx (esquema $8 A 8 B \quad B B \quad 8 A / / 8 c 8 d 8 d 8 c / 8 a 8 b 8 B 8 A$ ); en ella se formula, a través de paralelismos, figuras de dicción y correspondencias antitéticas, el conflicto amoroso de la acción, pero todavía de manera abstracta:

No es mi mal para sofrir

ni se puede remediar,

pues deciende de lugar

do no se puede subir. (vv. 1-4)

Como el propio argumento apunta, esta primera canción y el desarrollo de la égloga no son sino la traducción «de prosa a verso» del enfrentamiento entre Belisena y Flamiano, personajes de Questión de amor, en la jornada de la caza: después de que el joven confiese su amor desesperado, la muchacha se muestra enojada por su atrevimiento y lo desdeña marcando una barrera social que lo coloca en un plano inferior ${ }^{14}$.

Frente a la canción, los dos villancicos del final se adscriben a la corriente popularizante del Cancionero, contaminados también ya del elemento pastoril dramático. El primero (esquema $8 A 8 B \quad 8 B / / 8 c \quad 8 d \quad 8 d 8 c / 8 c \quad 8 a \quad 8 b \quad 8 b / / 8$ e $8 f \quad 8 f 8 e /$ $8 e 8 a 8 b 8 b$ ) abunda en un tema que apenas ha sido explotado durante la pieza dramática, pero que es frecuentísimo en el teatro de las primeras décadas del Quinientos: el del poder de Amor y su imperio extendido al estrato rústico ${ }^{15}$. El

${ }^{14} \mathrm{C}$. Perugini interpreta esta distancia como traslación de la realidad social del momento la impermeabilidad de clases a lo largo de la Edad Media (1995), p. 113, n.238, lo que apoyaría la hipótesis identificativa de Flamiano-Gerónimo Fenollet («Está claro que una nieta del rey, hija de duques, no podía estar al alcance de un simple gentilhombre como Flamiano», C. Perugini, 1995, p. 25)—. Pese a todo, creo que aquí la distancia tiene una operatividad funcional (la de construir el conflicto) y retórica (heredada de la tradición trovadoresca provenzal y la metáfora de la dama/ señor y el amante/ vasallo, donde aquella aparece inalcanzable, generalmente por su condición de mujer casada), de modo que no es necesaria una explicación extraliteraria, sino que se justifica desde el propio texto.

${ }^{15} \mathrm{La}$ omnipotencia del Amor (Omnia vincit Amor) era ya un tema privilegiado en los cancioneros del s. XV, desde las definiciones de amor en esparsas y canciones breves hasta la tradición de los triunfos de inspiración petrarquista y dezires alegóricos; vid. R. Recio (2007), (2012). Esta dirección de una poesía amorosa inserta en la tradición del amor cortés entronca ya con el elemento clásico (la Bucólica $X$ de Virgilio, el «Triunfo de Amor» de Ovidio, Am. 1, 2) a través de Dante y el Quattrocento italiano. El tema se trasvasa, como tantos otros motivos, de la lírica al teatro; en Italia adquiere un papel protagonista en el drama mitológico - y, por su influencia, en el drama pastoril; vid. Gerhardt, (1975 [1950]), pp. 92-93-, mientras que en España consolida su entidad dramática en la obra de Juan del 
segundo, de solo una mudanza ( $8 A 8 B 8 B / / 8 c 8 d 8 d 8 c / 8 c 8 b 8 B$ ), es un villancico dialógico (entre Guillardo y Torino) que alude a los síntomas del mal de amor en clave también pastoril.

Enmarcada por estas composiciones musicales, el cuerpo de la égloga se desarrolla en tres partes cuyo centro es el encuentro entre Torino y Benita, a modo de la codificada recuesta de amores (vv. 385-512). Hacia este núcleo se dirige toda la primera parte (vv. 1-384), en la que, tras un largo monólogo del protagonista (vv. 1-105), confía este a sus amigos, Quiral y Guillardo, su pesar amoroso (vv. 106384). No existe propiamente un desenlace que resuelva el conflicto dramático, los últimos doscientos versos (vv. 385-611) tienen un carácter epilogal y conclusivo desde el punto de vista del cambio de actitud: de nuevo se regresa a la conversación entre los tres amigos y Torino es convencido por Quiral para aceptar su sufrimiento como digna empresa de amor. Esta orientación feliz está claramente condicionada por la funcionalidad social del teatro como elemento festivo en las cortes (significativamente las obras se cierran normalmente con música y celebración), muchas veces representado en celebraciones de compromisos y bodas ${ }^{16}$. Al mismo tiempo, sin embargo, se puede leer como resolución del debate sobre la actitud del amante rechazado (condensación, a la vez, del debate sostenido a lo largo de la novela entre Flamiano y Vasquirán).

El monólogo inicial de Torino se inserta en la tradición bucólica virgiliana y su rehabilitación en el Renacimiento desde distintos géneros literarios, con la Arcadia (Venecia, 1502) de Sannazaro como referencia central. El modelo inmediato aquí es, sin embargo, Juan del Encina y su Égloga de Fileno, Zambardo y Cardonio (en adelante Éloga de Fileno), de la que toma también el molde métrico: coplas de arte mayor de esquema $A B B A A C C A^{17}$. Ahora bien, si en el salmantino el monólogo

Enzina: las Églogas VII y VIII, la Representación sobre el poder del Amor, la Égloga de Cristino y Febea (sin olvidar el poema transicional de Rodrigo de Cota, Dialogo entre el Amor y un viejo). En el Renacimiento, especialmente en el teatro (y posteriormente en la novela pastoril), la omnipotencia del amor desciende hasta el estrato rústico y no son solo los poetas cortesanos quienes sufren sus efectos. Esta «democratización del Amor», aparte de explicarse por la retórica del disfraz pastoril y mezclarse con el recurso teatral del contraste estamental derivado de la pastourelle (vid. infra, n. 25), está vinculada a una nueva conceptualización del hombre y su valía individual que, si bien no es generalizable a todos los autores, se encuentra bien representada en la Tragicomedia de don Duardos de Gil Vicente.

${ }^{16}$ J. P. W. Crawford (1921), (1922), p. 67 y ss.

${ }^{17}$ En Juan del Encina esta forma métrica (exclusiva en su producción teatral, en la que emplea normalmente el octosílabo) está justificada por la orientación elegíaca (estilo grave) de la obra, que finaliza con el suicidio de Fileno; así lo señala en su Arte de poesía castellana: «...que el arte mayor es más propria para cosas graves y arduas»; J. del Encina (1978), p. 26. En el caso de la Égloga de Torino, el suicidio solo aparece con función retórica (en relación a las metáforas cancioneriles de la muerte en vida) y, por tanto, el uso 
inicial es solo una breve introducción (dos coplas) que rápidamente introducen a un segundo personaje y encauzan la acción hacia el nudo y el desenlace fatal (suicidio), en el caso de nuestra égloga el monólogo se alarga a trece coplas y existe un desarrollo lírico y psicológico mayor en detrimento de la teatralidad.

El comienzo in medias res del lamento de Torino invita al auditorio a interesarse y "adivinar" la causa del personaje, de modo que se va modelando el conflicto a partir de la expectación creada; sus palabras informan de su caracterización como pastor, especialmente a través de los apóstrofes finales a sus atributos («vos mi çurrón| y vos mi rabel»: v. 57, «y vos mi cuchar| y vos mi barreña»: v. 63, «dexe mi çurrón| rabel y ganado /la yesca eslauon| barreña cuchar»: vv. 69-70), pero también de sus repetidas autoalusiones como pastor («vn pobre pastor»: v. 27, «vn pastorcillo»: v. 37, «tan triste pastor»: v. 53), y del espacio escénico, mediante deícticos y expresiones referenciales: pastura (v. 54), llano (v. 83), sierra (v. 83), bosques (v. 84), espesura (v. 84).

Y, aun así, el parlamento carece de fuerza dramática y se demora en la especulación conceptuosa propia de la poesía de Cancionero. Después de tres estrofas introductorias (vv. 1-24), dedicadas a las quejas del amor como dolor paroxístico y los tópicos de la muerte en vida o la dulce herida - más cercanas a la tradición medieval de la poesía cortesana castellana (desde la lírica gallegoportuguesa) que al «dolorido sentir» bucolizante y de filtro clásico propio del Renacimiento italiano-, el monólogo de Torino se organiza en tres niveles dialógicos: la imprecación contra el Amor (vv. 25-41), el apóstrofe a la soledad (vv. 41-48) y, en ella, a sus atributos de pastor (vv. 49-72) y, finalmente, tras una estrofa deíctica de transición (vv. 73-80), que sintetiza el problema y lo ubica ya en un tiempo y espacio concreto (los agoras anafóricos y los presentes eventuales referentes al momento de habla), un diálogo consigo mismo. Pese a todo, esta dialogicidad no es tanto teatral como mecanismo estilístico ya codificado en poesía para el análisis psicológico y expositivo. Los indicadores deícticos y las didascalias implícitas quedan ahogadas en la prolijidad verbal y especulativa. Por otro lado, las imprecaciones al Amor, la soledad y a los atributos del pastor siguen el modelo de la égloga enciniana citada.

Tras esta larga introducción, tienen lugar las escenas típicamente eclógicas: el doliente pastor (Torino) que cuenta sus cuitas amorosas a otros pastores (Guillardo y Quiral). Las confidencias están organizadas dualmente: un primer diálogo entre Torino y Quiral (vv. 159-256) y uno segundo entre Torino y Guillardo (vv. 333384 ), ambos precedidos por sendos diálogos entre los dos confidentes, Guillardo y Quiral (vv. 106-134 y vv. 257-332).

de este metro parece, más bien, una convencionalidad de género codificado a partir del modelo inmediato. 
Después de Torino, el segundo personaje que entra en escena es Guillardo, soporte de prácticamente todo el peso cómico en la obra. Se trata del pastor zafio que se corresponde con el Zambardo de la Égloga de Fileno (nótese, incluso, la similicadencia de los nombres) y está modelado sobre los caracteres del rústico de la primitiva égloga castellana (la que representa Lucas Fernández y la primera etapa de Encina) ${ }^{18}$. Este pastor se expresa en sayagués, lengua literaria derivada del leonés dialectal que abunda en expresiones léxicas estereotipadas (miafe, ahotas) y deformaciones fonéticas (aspiraciones de f- ante /wé/: huego, huerte, huesses; palatalización de laterales y nasales); y su discurso está cargado de referencialidades costumbristas (objetuales y espaciales) que refuerzan la ambientación pastoril (cabañas: v. 112, çurrón, cayado: v. 117, yesca, rabel: v. 118 , gancho: v. 127 , zagal: v.137) ${ }^{19}$. Esta forma expresiva, que contrasta con el registro cancioneril (léxico abstracto y fonética no dialectal) del monólogo de Torino, se contamina, sin embargo, también a este y a su amigo Quiral en las escenas que comparten con Guillardo. Más que mantener un decoro entre lenguaje y personajes, la adecuación estilística se establece entre lenguaje y situación: en las escenas cómicas (en las que está presente Guillardo siempre) se usa el sayagués y la teatralidad gira en torno al humor y malentendidos lingüísticos, mientras que en las escenas más propiamente de debate cancioneril (en las que Guillardo se encuentra ausente), el sayagués desaparece por completo. De cualquier forma, este personaje es el que más acentuadamente utiliza este lenguaje tosco y es él quien pone en marcha los motivos cómicos, en tensión con la gravedad patética del discurso de Torino.

Pues bien, Guillardo entra en escena a través de una serie de apartes, propiciados por la enajenación del protagonista, que no percibe la llegada de su amigo. El embeleso del pastor quejoso se hiperboliza y casi se caricaturiza con la actitud del rústico, quien, imposible de entender al doliente, formula unas conjeturas animalizadoras («Quiça la mordido| perro dañado / a qual canimal| o lobo rabioso»: vv. 113-114) que se convierten en una de las líneas de fuerza cómicas de la égloga: en efecto, inmediatamente después de comparar el dolor de Torino con un síntoma de la rabia, lo intenta atraer hacia así, como indica la didascalia implícita, con el gancho que se usa para acercar las ovejas: «quiero trauelle| del pie conel gancho», v. $127^{20}$

\footnotetext{
${ }^{18}$ Sobre el personaje del pastor-bobo, vid. J. Brotherton (1975), N. Salomon (1985) y A. Hermenegildo (1987). Recientemente, Sara Sánchez Hernández ha explorado la configuración del personaje del pastor en las églogas encinianas a partir de la utilería y vestuario (en prensa).

${ }^{19}$ Para un estudio lingüístico del sayagués, vid. D. Stern (1960) y J. Lihani (1973).

${ }^{20}$ Covarrubias define gancho como «Hierro retorcido para diversos usos, como el gancho que el pastor trae en su cayado, para asir la oveja con él de un pie, dicho por esto pedum pedi»; Covarrubias (1611) s.v. gancho).
} 
Llega después Quiral, introducido por las indicaciones proxémicas en el discurso de Guillardo («allí me parece| que viene quiral»: v. 131, «quiero llamarlo»: v. 133, «oyes quiral| allegate aca»: v. 134), y este le pide consejo para tratar la enajenación de su compañero. Se establece entonces un diálogo informativo en el que, aparte de explotar la comicidad mediante las conjeturas banalizadoras sobre el mal de amor («quiça aura perdido| o choto o borrego / y está maldiciendo| la res que lo cria»: vv. 141-142), la obra gana en dramaticidad gracias a la agilidad de la conversación y su riqueza en didascalias verbales (especialmente proxémicas y espaciales), que concretizan la acción ${ }^{21}$.

Una vez despedido Guillardo («sabes la via| da tu camino»: v. 158), comienza la entrevista entre Quiral y Torino (vv. 159-256). Quiral no es el pastor zafio que sí es Guillardo (por eso lo ha llamado este) y, sin embargo, en el primer encuentro con Torino asume, en parte, esta caracterización para establecer una tensión dialógica con implicaciones dramáticas y cómicas - en el fondo, se sigue también aquí el modelo enciniano, donde Cardonio, más juicioso que el tosco Zambardo, muestra una actitud inicial de incomprensión y lectura superficial de la situación ${ }^{22}$ - Ante los lamentos de Torino, cuyo discurso está guiado por la paradoja y la pasión para expresar su enajenación, Quiral recomienda cordura e inicia una serie de preguntas que estructuran el diálogo. Se trata de un mecanismo muy teatral que juega con la complicidad del público (quien conoce de sobra la causa amorosa del mal de Torino) y su impaciencia en gradación ascendente, empáticamente deseosa de que Quiral comprenda, por fin, qué le sucede a su amigo. Como digo, Quiral asume aquí el papel del rústico que no entiende el amor y una expresión muy cercana, en su zafiedad, a la del sayagués de Guillardo. Como nuevo Sempronio, interroga a Torino proponiendo causas materiales - la aegritudo amoris como enfermedad física («es mal de dellonbligo | o dolor de barriga»: v. 185, «es mal de costado | que a todos auança»: v. 190) o debida a preocupaciones económicas: vv. 193-196-, a las que Torino responde con la retórica propia del amante cortés («de muerte herido»: v. 198, «dessespero»: v. 200, «los males / que sufro y consiêto»: v. 206, «fallece esperança | crece tormento»: v. 207, «remedio no veo»: v. 208). Por fin, y ante las respuestas del quejoso, Quiral adivina la dimensión amorosa de sus cuitas («y dudo que creo | ques mal de amorío»: v. 202). Tras identificar referencialmente a la amada con la pastora Benita $-\mathrm{y}$ ofrecer una genealogía en clave que corresponde a Bona Sforza, «Belisena» en la novela (vv. 217-224)-, el diálogo vira de la comicidad rústica de tradición enciniana al debate cancioneril $\mathrm{y}$, aunque

${ }^{21}$ El potencial dramático que esconden las didascalias implícitas ha sido sistemáticamente estudiado para el teatro renacentista castellano por A. Hermenegildo (2001).

${ }^{22}$ No obstante, en la égloga de Encina, este pastor no adquiere nunca la postura idealista que tomará después Quiral (en relación a su correspondencia con el Vasquirán de la novela), sino que mantiene hasta el final su materialismo antiempático, como muestra su reacción ante la muerte del amigo. 
se conserva cierta dicción del sayagués (huerte: v. 230, huesse: v. 241, demoño: v. 242, miafe: v. 249), las cuatro estrofas siguientes (vv. 225-256) abandonan la concreción accional para derivar a la especulación conceptuosa del amor. Recogiendo los tópicos codificados a lo largo de la tradición - la dulce herida («siendo tu llaga | en si gloriosa»: v. 232), la teoría del amor a través de la vista y el amor hereos («tornando a miralla $\mid$ me crece mas pena»: v. 239), la enajenación del amante («que ando perdido | sin seso y sin tiento»: v. 246) - y en el característico estilo paradójico, abstracto y rico en poliptoton, se adelantan ya las posiciones enfrentadas de los dos pastores respecto al amor: mientras que Torino se duele del rechazo de la dama a su servicio (siguiendo la metáfora vasallática del amor cortés), Quiral cifra el gozo en la mera contemplación de la amada, aun en su desprecio y desdén ${ }^{23}$.

Quiral se despide de Torino, sin encontrar resolución a su debate. No existen (más allá del «Miafe pues quédate | con tu dolor», v. 249, de Quiral, a la que siguen unos versos del protagonista reflexionando sobre su dolor) didascalias explícitas o implícitas que indiquen la salida y entrada de personajes en escena. Suponemos el mutis de Torino y la aparición nuevamente de Guillardo, que inicia un diálogo con su compañero (vv. 257-332) cuya funcionalidad es doble: por un lado, la definición de Amor y su poder por parte de Quiral, quien se muestra ahora como refinado y culto aleccionandor del amigo torpe. Se trata de un ejercicio retórico en clave cancioneril («Un mal es quesentra | por medio los ojos (...) da pensamientos | dos mil a manojos»: vv. 273-280, «Es cosa que nace | dela fantasia (...) ni alla dondeesta | nunca entra alegría»: vv. 313-320), que entra en contraste con las burdas intervenciones de Guillardo. La abstracción del discurso del primero está contrarrestada por el del segundo, contrapunto cómico basado en la interpretación literal y física de las metáforas topicalizadas del amor cortés. Esta interpretación materialista, aparte de ser la clave humorística (con un incremento significativo del sayagués), está plagada de referencialidades concretas que desarrollan la dimensión teatral del diálogo: deícticos («aquí en nuestro aprisco»: v. 283, «conesta mi honda»: v. 307, «vuestras cabañas»: v. 293), sustantivos que remiten a la realidad del pastor

${ }^{23}$ Son, claro, las posiciones sostenidas a lo largo de Question de amor por Flamiano y Vasquirán, cuyo debate primario gira en torno a quién sufre más: el que es desdeñado por la amada y sabe que nunca podrá conseguir su favor (Flamiano) o aquel que, habiendo gozado de ella, la ha perdido para siempre porque ha muerto - $\mathrm{y}$, por tanto, jamás podrá volver a verla- (Vasquirán). La tradición de los casos de amor está ya en la tensó provenzal y continúa en la poesía de cancionero a través de los géneros dialogados. Las «Trece cuestiones» boccaccianas en el capítulo 4 de su Filocolo inician la vinculación entre la casuística amorosa y las ficciones sentimentales, vinculación que se hace efectiva en el ámbito pastoril con la Arcadia de Sannazaro (Venecia, 1502). Para un estudio de la quaestio de amor en la ficción sentimental y, específicamente, en la novela que me ocupa, vid. A. Chas Aguión (2001) y M. F. Aybar Ramírez (2001), pp. 183-186. 
y el espacio agreste, susceptibles de aparecer como elementos de atrezo (biuora, alacrán: v. 281, quajada, queso, pan: v. 288, castañas: v. 289, mançanas, bellotas, piñones: v. $290 \ldots$ ) y, en fin, una gran potencialidad quinésica que invita a la actuación imitativa y señaladora, ilustradora del discurso, en el actor que representa a Guillardo.

Una nueva intervención proxémica de Guillardo («Mas helo aquí torna | Torino turbado»: v. 329) da paso a la última escena de esta serie de confidencias entre los tres pastores. Aunque no hay ninguna indicación que lo explicite, suponemos que, si bien Quiral no hace mutis, queda ligeramente alejado de Torino y Guillardo, quienes sostienen una última conversación antes de la entrada de las pastoras. En estas siete estrofas (vv. 329-376), más bien transicionales respecto a la dinámica estructural, Guillardo pregunta ya directamente a Torino por la naturaleza de su mal (pues no ha entendido en absoluto las alambicadas explicaciones de Quiral). Sin recurrir al conceptismo abstruso, Torino se adapta a su interlocutor y rebaja su expresión hasta la sencillez más diáfana: «mi mal es cadoro | damor a benita / (...) y ella me trata | peor que aun moro» (vv. 337-340). Aun así, la ineptitud de Guillardo para entender el amor genera un nuevo discurso cómico y casi caricaturesco que insiste en la animalización del amante y la interpretación materialista y visceral: «assi te percosas | por una zagala / aue vergueña | de ti noramala / no digan que eres | algún verriondo» (vv. 354-356). Burlándose de la obsesión enajenante del amigo («Do yo al diablo | pastor tan sandio / que duna zagala | tan huerte sahunca»: vv. 369-370, «dalo al demoño [el mal de amor] | ques vn desuario / quesanda tras bobos | y los modorrece»: vv. 373-374), Guillardo avisa de la venida de Benita y recomienda a Torino esconderse en la verdura para, animalizando ahora a la amada como bestia causante del mal, dardearla y abatirla ${ }^{24}$. Reaparece ahora Quiral, que advierte a los compañeros bajar la voz por la cercanía de Benita; según parece dar a entender la acotación (una de las pocas en toda la obra: «Acercándose Benita habla Quiral»), este personaje no ha salido de escena, sino que ha permanecido, como dije, apartado.

Torino quiere, sin embargo, que Benita escuche sus penas y permanece a la espera de que la muchacha se acerque. Una nueva acotación da entrada a la intervención de Benita. Se inicia ahora la larga escena que constituye el centro de la égloga y que es, según se anunciaba en la introducción, la traslación de la entrevista entre Flamiano y Belisena que, en la novela, tuvo lugar el día de la caza («en la qual

\footnotetext{
${ }^{24}$ Las palabras de Guillardo son siempre las que mayor información didascálica aportan; en este caso, aparte de las motrices proxémicas (la entrada de Benita), dan cuenta del espacio escénico (baxo estas matas) y también están cargadas de potencialidad quinésica. Por otro lado, la mención de la compañera que acompaña a Benita («con otra zagala II que se anda trasella»: v. 363), la cual no interviene verbalmente en la acción, es otro indicio más para la proyección representativa de la obra, que contempla actantes mudos en su desarrollo.
} 
se contiene pastorilmente todo lo que en la caça con belisena paso», p. 100). Aunque no se explicita, de nuevo suponemos que el resto de personajes, sin desaparecer de la escena, queda apartado en un segundo plano para focalizar la atención en la conversación entre Torino y Benita (vv. 385-512): así parece sugerirlo el saludo de la joven, dirigido a un interlocutor plural («Questays hablando | a solas pastores»: v. 385$)$.

El encuentro con la amada no está en el modelo enciniano de la Égloga de Fileno, pero sí estaba codificado en la tradición dramática eclógica a partir de la recuesta de amores (desarrollo de la pastorela lírica medieval). Sin embargo, la escena no sigue el patrón del teatro salmantino (al estilo de la Égloga en requesta de unos amores de Juan del Encina o la Farsa o cuasi comedia de una doncella de Lucas Fernández) sino que muy pronto abandona todo indicio de teatralidad y se presenta como una sucesión de dieciséis coplas líricas que desarrollan los tópicos del amor cortés. El sayagués desaparece por completo y prácticamente también la ambientación pastoril. Aunque Benita interviene en tres ocasiones - al entrar (vv. 385-392), en una segunda réplica (vv. 409-420) y al final, para despedirse airada (vv. 497-506) - el grueso del discurso pertenece a Torino (92 de 127 versos) y es prácticamente un monólogo en el que comunica su pena de amor a la amada ${ }^{25}$. El punto de arranque es la censura de la joven a las pretensiones de Torino desde el criterio de desigualdad de clases («que busques y siruas | tus pares e iguales»: 391); esta desigualdad está justificada dentro del texto por la diferente categoría social, aun dentro del mundo pastoril, de Benita («La nieta de aquel | que hue mayoral»: v. 217) y Torino (A quien Guillardo define como zagal en el sentido de «pastor mozo, que está subordinado al rabadán en el hato» ${ }^{26}$ ). Como sugiere Carla Perugini (vid. supra, n. 5), quizá se trate de la traslación, primero a la novela Questión de amor y luego a la égloga, la situación real de los personajes en clave retratados (Gerónimo Fenollet y Bona Sforza); sin embargo, creo que esta barrera es más bien retórica la codificación de la diferencia entre señor y vasallo metaforizada en el amor cortés - que funciona además operativamente a la hora de construir el conflicto (es el mismo modelo literario, por otro lado, que funciona en la relación CalistoMelibea). Pues bien, ante esta censura Torino apela a la ingobernabilidad racional del amor y alude a la teoría del amor por la vista para justificarse («estos [mis ojos] man hecho | señora seruiros»: v. 395); después de asumir su rol de siervo y explicar

\footnotetext{
${ }^{25}$ Hay un error de atribución en la edición de C. Perugini (1995), p. 116, en el v. 505, que sigue la edición de 1513. Los vv. 505-506 todavía pertenecen al discurso de Benita («Pues creyme pastor | y haz lo que digo»), y es en el v. 507 cuando empieza a hablar Torino («Miafe benita | imposible seria»). Como señala P. Andrachuk, (2006, n. 213-214), la atribución errónea fue corregida en la edición de Salamanca de 1519 y siguientes.

${ }^{26}$ Diccionario de Autoridades, s.v. zagal. La subordinación a un superior refleja también en estas palabras del mismo Guillardo, unos versos antes: «O si con su amo | quiça si ha reñido / (...) mas el no harie | por poca soldada» (vv. 121-122).
} 
que su único reproche es que ella no acepte el servicio («pues que yo no quiero que mi mal merezca / sino que querays | que yo lo padezca»: vv. 398-399), recrimina a Benita su dureza y crueldad para con él (la belle dame sans merci), culpabilizándola de su actual dolor. La importunación de la muchacha, que insiste enojada en la diferencia de clases, da paso ya al largo parlamento de Torino. Reúne en él todos los tópicos que configuran el concepto cortesano de amor: la teoría fisiológica del amor por los ojos y la impresión indeleble de la imagen de la amada en el alma del enamorado (vv. 421-428), la imaginería de las flechas de Cupido (vv. 429-432), la religio amoris — no solo mediante el guiño celestinesco («dire que Benito / so (...) después que te vide»: vv. 447-449), sino alzándola a la categoría divina en calidad de inmortal: «porques inmortal [el alma de Torino] | estando tu enella» (v. 466) - la paradoja de la muerte en vida y el deseo de morir para dejar de sufrir, o las metáforas del amor como océano («mis ondas crecidas $\mid$ de tanta passion»: v. 461) y del amor como fuego («el fuego de dentro | la causa prouoca»: v. 456). Todo ello a través de un léxico técnico y abstracto, articulado en una expresión conceptista y rica en figuras de dicción (poliptoton, derivatio, paronomasia), similicadencias, antítesis, paradojas, oxímora y paralelismos bimembres (sinonímicos y contrastivos) ${ }^{27}$. Estos tópicos no están enhebrados, sin más, en una enumeración descriptiva de un estado amoroso, sino que se insertan en un discurso argumentativo cuya conclusión formula Torino al final, como único consuelo a su cuita: su muerte por amor originará la culpabilidad y el arrepentimiento de la dama que en vida lo desdeñó — «pues yo sere muerto | y tu arrepentida / de ver que sin culpa $\mid$ assi me mataste / (...) que tuyo es el cargo | pues mal le trataste»: (vv. 483-484, v. 488) - y esa culpabilidad futura recompensa al enamorado en su dolor actual — «o quan contento | mi cuerpo deshecho / en la sepultura (...) / con ver esta gloria | y mi alma contigo / haciendo te mientes $\mid$ del mas que mas hecho» (vv. 493-496) —. La argumentación sigue de cerca el pasaje de

\footnotetext{
${ }^{27}$ He obviado las referencias por su evidencia y abundancia. Sin querer ser exhaustiva, doy a continuación una serie de ejemplos ilustradores de este estilo. Respecto al vocabulario, son frecuentes los sustantivos abstractos que remiten al ámbito jurídico y la institución del vasallaje (servicio, querella, cativo) y, sobre todo, al proceso fisiológico y psicológico del amor (pena, tormento, gloria, passion, peso tan graue, alma, corazón, entrañas, ojos). En cuanto a las figuras de dicción que juegan sobre una base léxica: tanto magraua/ con peso tan graue (v. 458, paronomasia); «Si tal fantasía | me juzgan ser loca / más loco sería (...)» (vv. 449-450), «(...) me juzgan ser loca / (...) quien tal me juzgase» (vv. 449-450), «(...) te viesse y mirasse / verías ques justo (...)» (vv. 451-452), «(...) de serme (...)/ siendo (...)/ yo serte (...)» (vv. 477-478), «me basta que baste» (v. 481, poliptoton). Ejemplos de similicadencias son: «te viesse y mirasse» (v. 451), «mataste/causase/ trataste» (v. 484, v. 485 , v. 488); antítesis, oxímora y paradojas: «yo muriendo | es fuerza que biua» (v. 465), «lo que siendo libre/ de mi no podrá» (v. 470), «siendo contento | yo serte catiuo» (v. 478), «hacerme contento | perdiendo la uida» (v. 482).
} 
la cacería en Questión de amor (pp. 77-80), tanto en el contenido como en la enunciación formal, siendo casi una versificación. Como allí, la escena termina con la ira acrecentada de la joven, que le reprocha vanidad y ofensión a la vez que se declara tajantemente su enemiga y se marcha ${ }^{28}$. A la salida airada de Benita Torino responde, de nuevo en tono quejoso, con el tópico del amante enajenado a través de la metáfora locativa (la amada no parte porque está eternamente en el alma del enamorado y, a la vez, este parte con ella porque su alma ya no le pertenece: es «cautiva» de su señora). Las alusiones espaciales y deícticas que propicia esta metáfora («benita estaqui | torino estalla»: v. 511) seguida luego literalmente por Guillardo («la otrastalli | y diz questaqui»: v. 516) posibilitan un desarrollo gestual y quinésico y reconducen la acción al planteamiento teatral inicial.

Tras cuatro estrofas de transición (vv. 513-540) en las que, reunidos los tres pastores, destaca la voz de Guillardo como elemento cómico otra vez, con su empecinada literalidad materialista, Quiral despide a su torpe amigo, desesperado ante su necia incomprensión («calla modorro | que no es so [sino] penado (...)»: v. 527, «vete al demoño | tu y tus consejas / piensas ques esto | andar tras ouejas / pues tu nolontiendes | dexalo estar»: vv. 538-540). La escena de cierre no pone ningún desenlace al conflicto como acción (Torino desdeñado por Benita), sino que se resuelve por cese del diálogo y acuerdo de opiniones en el debate verbal. En realidad, estas últimas coplas de Quiral y Torino (vv. 544-611), si bien se insertan en la tradición de la égloga lírica (la reflexión de dos pastores sobre casos de amor), tiene mucho también de tensó y joc partit o, en la forma castellana heredera, de preguntas y respuestas como esquema poético cortesano. Se trata de oponer dos puntos de vista respecto a un asunto concreto buscando el triunfo de uno sobre otro.

De nuevo, el diálogo tiende hacia el estatismo lírico y abstracto, especialmente a partir del v. 576, donde se abandona la concreción de la historia y los nombres de los personajes. En el mismo estilo conceptuoso del encuentro con Benita (e incluso en mayor grado) se articula un debate que desarrolla las posturas adelantadas al comienzo (y que es, en el fondo, la equivalencia de la discusión sostenida por Flamiano y Vasquirán en la novela). La conversación arranca del topos de la muerte de amor, cuya presencia protagonista en las dos primeras estrofas parece remitir al modelo enciniano de la Égloga de Fileno, donde la muerte sí funciona como desenlace operativo. En este caso es convención retórica desde la que sustentar el debate, pues no se pasa de las expresiones paradójicas topicalizadas («como y no vees | en mi que ya muero»: v. 548, «pues muero biuiendo | y remedio no espero»: v.

${ }^{28}$ El agravio que le reprocha Benita — como Belisena en la caza (p. 79) — no se refiere solo al atrevimiento de sus pretensiones, dada la diferencia de clases, sino a la propia comunicación del amor que, al hacerlo público, puede dañar su honra y su estado en la esfera social. Al final, Quiral también le reprochará no haber mantenido el secreto de amor (vv. 570-574), pero ya no por las consecuencias en sociedad, sino asumido como arduo mérito del perfecto amante cortés. 
552, «más es que morir | contino que muera / penando en la vida $\mid$ y mil muertes sufriendo»: vv. 559-560). Los lamentos de Torino y su continuo reclamar el beneplácito de la dama al servicio de amor despiertan las réplicas de su amigo, quien expone su concepción del deber del amante: para Quiral, el servicio de amor es incondicional; al asumirlo, el enamorado adquiere un compromiso ético consigo mismo y su deber es mantenerse fiel pese al desdén y rechazo. El sufrimiento es consustancial al sentimiento amoroso («tan grandes el bien | quan grandes el mal / porquesta es la ley / perfecta damor»: vv. 587-588) y el gozo es mayor cuanto mayores son los obstáculos y esfuerzo exigido («que quanto más peno | mi gloria es mayor»: v. 584). La filosofía masoquista que Quiral ofrece a Torino es la que se configura en la poesía trovadoresca de la escuela francesa y que llega al paroxismo sufriente en la tradición gallego-portuguesa (continuado también en el Cuatrocientos castellano). Desde esta perspectiva, al amante no le queda otra esperanza que recrearse en el dolor gozoso del amor solo desde la contemplación del objeto amado ${ }^{29}$.

El debate termina con la «victoria» de Quiral, que logra convencer a Torino: «Al fin tu consejo | aure de seguir / (...) quiero por fuerça | de grado seruir» (vv. 605611). Frente al final trágico enciniano (si bien violentado allí con un humor áspero), la Égloga de Torino se resuelve en la tónica propia de la novela: desde la intrascendencia festiva (habitual, por otro lado, en este tipo de piezas dramáticas, vinculadas al ámbito cortesano y representadas normalmente en eventos celebrativos).

La decisión de Torino de servir incondicionalmente a Benita está apostillada por la intervención de Guillardo en clave cómica. Se trata de una especie de epílogo que, si bien no llega a dialogar con el auditorio (pidiendo beneplácito o despidiéndose), sí que contribuye a difuminar los límites entre ficción y realidad con la inserción de la música y el baile. En efecto, aunque los villancicos todavía mantienen las identidades pastoriles de la égloga, sirven de puente para incorporar al público, hasta ahora en silencio, a la fiesta global de la que participan todos. Actores y

${ }^{29}$ La visión espiritualizada del amor que triunfa aquí es señalada por T. Ferrer Valls como excepcional respecto al erotismo carnal, que es característico del teatro español del primer Renacimiento. Para ella, la descarnalización se explica, en gran medida, por el procedimiento en clave de toda la obra, que remite a personas reales: «Torino es, pues, trasunto del caballero valenciano Jeroni Fenollet, y su pastora, Benita, de Bona Sforza, hija del duque de Milán y futura reina de Polonia, ambos residentes por aquellas fechas en Nápoles. La égloga y el amor se plantean así como un juego social de disfraces; la distancia social entre los personajes reales — creo- es determinante aquí de la descarnalización de las relaciones de los personajes de la ficción. Benita precisamente aconseja a Torino que se enamore de sus "iguales". Algo similar a lo que ocurre en la novela pastoril en clave de Gaspar Mercader El Prado de Valencia, publicada en 1600»; T. Ferrer Valls (1990), p. 52, n.2. 
espectadores pertenecen a un mismo grupo social y, así, «la égloga acabada, flamiano se torno a su posada y tornaron a la fiesta vestidos de mascara»: la celebración continúa y todos son protagonistas otra vez $z^{30}$.

El estudio detallado de la Égloga de Torino permite ilustrar el espacio de creación dramática y su idiosincrasia en las cortes hispánicas del primer Quinientos. La propia ficción narrativa en la que se inserta, Questión de amor, es un fresco iluminador del fasto cortesano en el que nace este teatro y donde el elemento escénico forma parte del todo mayor que es el evento social, la fiesta. A este propósito, Teresa Ferrer Valls subraya el intercambio recíproco de material entre el fasto y la propia representación dramática: «La historia de la práctica escénica cortesana en el Siglo de Oro estaba llamada a ser una historia de préstamos entre fasto dramático cortesano y representación cortesana» ${ }^{31}$.

$\mathrm{Y}$ es el género eclógico, en palabras de Joan Oleza, «el primer signo de identidad» de este teatro cortesano ${ }^{32}$. El pastor enciniano más primitivo, que arranca de la tradición litúrgica navideña, pasa muy pronto (Églogas VII y VIII de Encina, en el Cancionero de 1496) a formar parte del espectáculo nobiliario de tema profano $^{33}$; en su rudeza y comicidad, rompe el decoro y construye el marco festivo desde la dimensión carnavalesca y es el personaje eje de la que Joan Oleza denomina «égloga rústica» ${ }^{34}$. Cuando, a lo largo de las primeras décadas del s. XVI, se desarrolle un modelo de pastor cortés más sofisticado a partir de las influencias italianas y la penetración clásica, el pastor rústico no desaparece, sino que es absorbido por el modelo eclógico clasicista que explota teatralmente el contraste entre ambos. Así lo hace Encina en la Égloga de Fileno y, siguiendo el ejemplo, el autor de la Égloga de Torino ${ }^{35}$.

${ }^{30}$ T. Ferrer Valls (1993), p. 23, señala como característica de los espectáculos cortesanos esta continuidad entre vida y representación y apunta como «uno de los principales alicientes que ofrecía par el público cortesano este tipo de entretenimientos teatrales era precisamente su propia participación como actores amateurs en las representaciones». Por otro lado, R. E. Surtz (1979), p. 75, partiendo de los estudios antropológicos de J. Huizinga (1930 [1919]), destacó la condición performativa de la propia sociedad cortesana desde la última Edad Media: «The ease with which these courtiers slip in and out of their roles as spectators and participants can be related to a more general medieval tendency to see oneself as playing a social role in a rigidly hierarchic chivalcric society».

31 (1993), p. 19.

32 (1986), p. 171.

${ }^{33}$ Gerhardt (1975 [1950]), pp. 130-135.

${ }^{34}$ J. Oleza (1984c), pp. 190-193.

${ }^{35}$ Habla J. Oleza, (1986), p. 197, de este enfrentamiento entre pastor rústico y pastor cortés como uno de los elementos fundamentales de la tradición pastoril. En realidad, el contraste (generador de comicidad $\mathrm{y}$, a la vez, de teatralidad), es una adaptación de la típica contraposición entre mundo nobiliario y mundo campesino que explota ampliamente la pastourelle francesa de la Edad Media, concebida siempre desde la perspectiva del receptor 
La crítica ha señalado la Égloga de Fileno como modelo evidente de la pieza. Los formantes macroestructurales y argumentales son muy semejantes: el pastor quejoso por el amor rechazado, el amigo confidente de raíz virgiliana, el pastor zafio que no entiende el problema amoroso (falta aquí, como vimos, el suicidio en el desenlace).

Pero la dramaticidad de la obra es más débil que en la de Encina y tiene siempre mayor fuerza en las escenas cómicas, donde los diálogos se hacen más agiles y contribuyen más sólidamente a construir la acción desde los apartes y las didascalias implícitas: alusiones al espacio escénico, elementos de atrezo, indicaciones motrices quinésicas y proxémicas. Estas escenas de humor rústico, casi entremesil, siguen básicamente la tradición más temprana del teatro enciniano (el llamado «modelo rústico» ${ }^{36}$ ); sin embargo, falta la creación de un conflicto potente y sostenido desde el punto de vista teatral, la situación del comienzo (Torino sufriendo de amor por Benita) es prácticamente la misma que en el final ${ }^{37}$.

En cuanto al elemento espectacular y paraverbal relacionado con la puesta en escena, el propio género de la obrita (el modelo bucólico antes citado) condiciona su escasa atención a lo escenográfico y el lujo material más propio del fasto ${ }^{38}$. No se trata tanto de la pérdida de material performativo en el paso al texto impreso ${ }^{39}$, reconstruible, como hemos visto, a través de las didascalias implícitas del texto (el pino inicial y las alusiones a un espacio dramático rural, el laúd, los aperos del pastor, la caracterización de los personajes a través del vestido, la colaboración de la música y el canto ${ }^{40}$; sino de una atención prioritaria a la palabra ${ }^{41}$.

aristocrático; cfr. Gerhardt (1975 [1950]), pp. 35-37. La pastorela lírica medieval y su contraste de estamentos es, por otra parte, otro de los formantes del teatro de pastores español más temprano: su huella aparece claramente en las Églogas VII-VIII y la Representación sobre el poder del Amor de Encina, o en la Farsa o cuasi comedia de una doncella de Lucas Fernández.

${ }^{36}$ J. Oleza, (1986), p. 197.

${ }^{37}$ Cfr. Oleza, (1986), p. 197. La creación de un conflicto dramático más o menos consistente es una de las conquistas de las últimas piezas encinianas: en Fileno, Zambardo y Cardonio, las lamentaciones desesperadas del primero se resuleven con el suicidio final; el propósito ermitaño de Cristino es vencido finalmente por Amor a través de la ninfa Febea en Égloga de Cristino y Febea. Bastante más complejo, el conflicto inicial de los amantes separados en Égloga de Plácida y Victoriano queda resuelto por el suicidio y la resurrección paganizante de la joven.

${ }^{38}$ «La égloga pastoril de amores idealizados es, fundamentalmente, teatro de la palabra (al contrario que las del modelo costumbrista puro), y de la palabra poética. Es más literatura que espectáculo, y acoge en su seno los temas serios de la cultura cortesana»: J. Oleza (1984a [1981]), p. 18.

${ }^{39}$ Cfr. J. San José Lera (2013).

${ }^{40}$ Cfr. F. Vigier (2006), p. 62. 
La debilidad del elemento dramático (más que por la pobreza material escenográfica, por el propio diseño de la obra) evidencia una tradición muy joven todavía y poco desarrollada. Aparte de la finalidad principalmente social, no hay una conciencia definida y autónoma de creación teatral; el impulso literario es, más bien, un ejercicio retórico: el autor ensaya el género de la égloga como ensaya otros tantos moldes poéticos y prosísticos de tradición cortesana a lo largo de la novela ${ }^{42}$.

En este sentido, destaca poderosamente la tradición de la lírica de Cancionero como pilar fundamental (junto a la impronta eclógica citada) de la Égloga de Torino. Como estudié arriba, las partes en las que se abandona el componente cómico tienen siempre un desarrollo abstracto y conceptista, y casi olvidan la concreción de la historia escenificada (el marco espacial agreste, la caracterización pastoril, el caso individual de Torino). El conflicto articulado en torno a los personajes es solo el pretexto (como en la novela) para reflexionar extensamente sobre el concepto de amor y ejercitarse en su plasmación retórica según la tradición del Cancionero medieval.

Puede parecer extraño, por otro lado, que el anónimo autor de la Questión, indudablemente vinculado a las cortes orientales de la Península y el entorno napolitano, revele una influencia tan escasa de la tradición grecolatina, siendo esta el eje de la actividad cultural en la Italia del momento.

Los elementos que podríamos considerar «renacentistas» —el bucolismo, la relación empática del enamorado y la naturaleza, la importancia de la amistad y la figura del amigo confidente - están muy superficialmente apuntados aquí y son todavía motivos adosados que no se corresponden con la cosmovisión profunda del texto. La relación que J. P. W. Crawford y luego J. Oleza han establecido con el drama italiano se basa más en el uso de personajes «en clave» y datos externos relativos al contexto de acción del anónimo autor (corte valenciana - corte

${ }^{41}$ Las numerosas alusiones a los atributos pastoriles (çurron, rabel, cuchar, barreña, caydo) sugieren la presencia material de elementos de atrezo, que propiciarían la deixis gestual de los actores. Las alusiones al prado y su entorno (pastura, cabañas, exidos), así como el ganado, cuya presencia se menciona a lo largo de la obra, requerirían, quizá, un mayor despliegue escenográfico que podría omitirse —el espacio narrado al que se refiere M. C. Bobes Naves (1994), pp. 254-, dado el carácter recitativo y eminentemente verbal de este tipo de obras. Sin embargo, no es difícil pensar en un decorado heredero de los entremeses medievales (no tanto del tratadismo escenográfico renacentista, inspirado en la tradición clásica y la obra vitrubiana). Sobre el desarrollo del escenario bucólico en el Renacimiento puede verse M. Prieri (1983).

${ }^{42}$ Recuérdese que, no solo el teatro, sino la literatura en general se concibe en este momento como práctica colectiva y social: composiciones líricas recitadas en voz alta, justas poéticas y concurso improvisado de versos, lecturas en voz alta, novelas en clave... Sobre el carácter oral y dramatizable de la literatura cortesana puede consultarse R. E. Surtz (1979), pp. 161169; M. Frenk (1982), A. Rodado Ruiz (1995), J. M. Díez Borque (1987), pp. 490-491, o A. Bustos Tauler (2008). 
napolitana) que en la construcción interna de la obra ${ }^{43 .}$ El drama pastoril italiano es, por otra parte, un concepto demasiado amplio con un desarrollo geográfico desigual: la égloga dramática tiene su núcleo originario en las cortes septentrionales (Mantua, Ferrara, Urbino, Florencia), a partir del desarrollo de la bucólica lírica de tradición boccacciana y petrarquesca en torno al círculo médiceo y las Bucoliche Elegantissime sienesas de 1482. La corte napolitana se presenta como un centro cultural receptivo y sincrético en el que, desde mediados del s. XV, se instaura un nuevo gusto literario de cuño español, importado por Alfonso el Magnánimo. A pesar de las intensas relaciones con los centros del norte, el humanismo napolitano está marcado por un fuerte carácter medieval vinculado al fasto cortesano aragonés $^{44}$. Así, la poesía pastoril importada de la Toscana en las últimas décadas del Quattrocento adquiere desde el principio el carácter oral y recitativo típico de la literatura cortesana, pero su faceta dramática se desarrolla básicamente en la dimensión propagandística del alegorismo político, tan caro a las cortes de la última Edad Media, relegando el elemento amoroso a un segundo plano ${ }^{45}$.

La Égloga de Torino, por tanto, no pertenece al contexto plenamente renacentista, impregnado del espíritu humanista y clasicista que respira, por ejemplo, Florencia, sino que está ligado a un centro ecléctico y transicional como lo es el del Nápoles de finales del XV: asomándose ya a las innovaciones del norte, el peso de la tradición medieval y su fasto cortesano es todavía muy marcado (como lo será también en Valencia). Por eso no resulta extraña la escasa presencia del elemento clásico en la Égloga, que, cuando aparece, está tomado del texto intermediario modelo, la Égloga de los tres pastores de Encina, o es muy superficial (así, el motivo del pastor cantando sus penas de amores bajo el pino al comienzo de la égloga, relacionado directamente con la Prosa I de la Arcadia sannazariana $)^{46}$.

${ }^{43}$ Cfr. J. P. W. Crawford (1921), pp. 69-71 y Oleza (1984c), p. 195, (1986), p. 178.

La dimensión alusiva del disfraz pastoril estaba ya en Virgilio. En la segunda mitad del s. $\mathrm{XIV}$, la pastorela francesa asume naturalmente un carácter alusivo que responde al milieu cortesano en el que se cultiva. Las Pastourelle de Froissart inauguran este modelo en Francia, que es seguido por los Rhétoriqueurs; vid. M. Gerhardt (1975 [1950]), pp. 59-60. El carácter alegórico de la bucólica es también rasgo definitorio en las églogas latinas de Petrarca, así como en las obras boccaccianas de tinte pastoril (L'Ameto, Ninfale Fiesolano). Más tarde, cuando comienza la producción de las primeras églogas recitativas y dramáticas a finales del XV en las cortes italianas septentrionales, se mantiene también la condición alegórica de lo pastoril (así, la égloga Tirsi de Castigione, recitada en la corte de Urbino durante el Carnaval de 1506), y continuará siendo característica del género pastoril, en su dimensión teatral o narrativa, a lo largo de los siglos XVI y XVII; M. Gerhardt, (1975 [1950]), pp. 90-92.

${ }^{44}$ M. Pieri (1985), pp. 71-72.

${ }^{45}$ M. Pieri (1985), p. 81.

${ }^{46}$ Cfr. J. Oleza, (1986), p. 178, n. 152. 
La fuerza de lo medieval en esta pieza dramática de comienzos del s. XVI (también en el resto de la novela) ilustra la encrucijada entre lo antiguo y lo moderno, la intersección en la que un humanismo aún embrionario se insinúa tímidamente al lado de una tradición sólida y activa. De hecho, la poesía de Cancionero, que es (junto a la égloga enciniana), la fuente central de esta pieza, no se extingue nunca; readaptada y solapada, pervivirá en la obra garcilasiana y, a través de ella, en toda la poesía hispánica del Siglo de Oro.

\section{Obras citadas}

ANDRACHUK, Gregory Peter (ed.): vid. Questión de amor, 2006.

ARZOCCHI, Francesco de, Hyeronymo BENIVIENI, Jacopo Fiorino de BUONINSEGNI, Ilaria MERLINI y Bernardo PULCI: Bucoliche Elegantissime, Florencia, Antonio di Bartolommeo (Miscomini), 1482.

ASENSIO, Eugenio: «De los momos cortesanos a los autos caballerescos de Gil Vicente», Anais do Primero Congresso Brasileiro da Língua Falada no Teatro, Ministério da Educação e Cultura, Rio de Janeiro, 1958, pp. 163-172; reimpr. en Estudios portugueses, Paris, Fundação Calouste Gulbenkian, Centro Cultural Portugues, 1974, pp. 25-36.

AUBRUN, Charles Vincent: «Sur les debuts du théâtre en Espagne», en Hommage à Ernest Martinenche, París, 1939, pp. 293-314.

_, «La chronique de Miguel Lucas de Iranzo: Quelques clartés sur la genèse du théâtre en Espagna», Bulletin Hispanique, XLIV (1942), pp. 81-89.

AYBAR RAMíreZ, María Fernanda: La ficción sentimental del siglo XVI, Tesis doctoral dirigida por Nicasio Salvador Miguel, Universidad Complutense de Madrid, 1995.

BECKER, Danièle: «Musique et théâtre dans la Peninsule Ibérique de la fin du XV siécle au milieu du $\mathrm{XVI}^{\mathrm{e}}$ siècle», en I. Mamczarz (ed.), Dramaturgie et collaboration des arts au théâtre, Roma, Olschki, 1993, pp.103-120.

BEHAR, Pierre and Helen WATANABE-O'Kelly (eds.): Spectaculum Europaeum: Theatre and Spectacle in Europe: Histoire du Spectacle en Europe (15801750), Wiesbaden, Harrassowitz, 1999.

BLAY MANZANERA, Vicenta: «Espectáculos cortesanos y parateatralidad en la ficción sentimental», Bulletin of Hispanic studies, Vol. 74, 1 (1997), pp. 6192.

Bobes NAVes, $\mathrm{M}^{\mathrm{a}}$ del Carmen: «El teatro», en Darío Villanueva (coord.), Curso de teoría de la literatura, Madrid, Taurus, 1994, pp. 241-268.

BOCCACCIO, Giovanni: Filocolo, a cura di A. E. Quaglio, in Tutte le Opere, a cura di Vittore Branca, Milano, Mondadori, 1964-1992, vol. I.

- L'Ameto o Comedia delle ninfe florentine, a cura di A. E. Quaglio, in Tutte le Opere, a cura di Vittore Branca, Milano, Mondadori, 1964-1992, vol. II. 
, Ninfale fiesolano, a cura di Armando Balduino, in Tutte le Opere, a cura di Vittore Branca, Mondadori, 1964-1992, vol. III.

BOUZA, Fernando: «El espacio en las fiestas y en las ceremonias de corte. Lo cortesano como dimensión», en Fernando Villaverde (ed.), La fiesta en la Europa de Carlos V: [exposición] Real Alcázar, Sevilla, 19 de septiembre-26 de noviembre 2000, Madrid, Sociedad Estatal para la Conmemoración de los Centenarios de Felipe II y Carlos V, 2000, pp. 155-173.

BROTHERTON, John: The Pastor-Bobo in the Spanish Theatre Before the time of Lope de Vega, London, Tamesis Books, 1975.

BUSTOS TAULER, Álvaro: «Villancicos pastoriles de deshecha en el cancionero de Juan del Encina (1496): entre poesía de cancionero, música renacentista y teatro de pastores», en Javier San José Lera (dir.), La fractura historiográfica: las investigaciones de la Edad Media y Renacimiento desde el tercer milenio, Salamanca, SEMYR, 2008, pp. 507-517.

CASTIGLIONE, Baldesar y Cesare GONZAGA: Thyrsis. Ed. de Bruno Maier en Il libro del Cortegiano, con una scelta delle Opere minori di Baldesar Castiglioni, Torino, U.T.E.T., 1961, pp. 547-571.

CÁTEDRA GARCÍA, Pedro M.: «Fiestas caballerescas en tiempos de Carlos V, », en Fernando Villaverde (ed.), La fiesta en la Europa de Carlos V: [exposición] Real Alcázar, Sevilla, 19 de septiembre-26 de noviembre 2000, Madrid, Sociedad Estatal para la conmemoración de los centenarios de Carlos V y Felipe II, 2000, pp. 93-117.

CHAS AGUIÓN, Antonio: «Qüestion de Amor y la tradición medieval de las cuestiones de amon», Insula: revista de letras y ciencias humanas, $\mathrm{n}^{\circ} 651$, (2001), pp. 20-22.

CRAWFORD, J.P.W.: «Early Spanish wedding plays», Romanic Review, XII (1921) pp. 370-384.

_. Spanish Drama before Lope de Vega, Filadelfia, University of Pennsylvania Press, 1937.

CROCE, Benedetto: La Spagna nella vita italiana durante la Rinascenza, Bari, Laterza, 1917.

De Mata CARRIAZO, Juan (ed.): Hechos del Condestable don Miguel Lucas de Iranzo (Crónica del siglo XV), Madrid, Espasa Calpe, 1940.

DÍEZ BORQUE, José $\mathrm{M}^{\mathrm{a}}$ : «Liturgia-fiesta-teatro: órbitas concéntricas de teatralidad en el siglo XVI», Dicenda. Cuadernos de Filología Hispánica, 6 (1987), pp. 485-499.

ENCINA, Juan del: Cancionero de las obras de Juan del Encina, Salamanca, 1496; ed. facsímil de Emilio Cotarelo y Mori, Madrid, Real Academia Española, 1928 [reed. 1989].

- Obras completas I. Arte de poesía castellana, Poemas religiosos y Bucólicas, Ana María Rambaldo (ed.), Madrid, Espasa-Calpe, 1978.

_, Teatro completo, ed. de Miguel Ángel Pérez Priego, Madrid, Cátedra, 1991. 
FERNÁNDEZ, Lucas: Farsas y églogas al modo y estilo pastoril y castellano, Salamanca, Lorenzo de Liom Dedei, 1514.

FERRER VALLS, Teresa: «El erotismo en el teatro del primer Renacimiento», Edad de Oro, 9 (1990), pp. 51-68.

_, La práctica cortesana, London, Tamesis Books, 1991.

-, Nobleza y espectáculo teatral (1535-1622). Estudio y documentos, UNED, Universidad de Sevilla, Universidad de Valencia, Serie "Textos teatrales del Siglo XVI", 1993.

, "Corte virreinal, humanismo y cultura nobiliaria en la Valencia del siglo XVI», en E. Berenguer (coord.), Reino y ciudad. Valencia en su historia, Madrid, Fundación Caja Madrid, 2007, pp. 185-200.

FRENK ALATORRE, Margit: " "Lectores y oidores". La difusión oral de la literatura en el Siglo de Oro», en G. Bellini (ed.), Actas del VII Congreso Internacional de Hispanistas, Roma, Bulzoni, 1982, pp. 101-123.

GARCIA, Michel: «Les fêtes dans le roman sentimental à la fin du XVe siècle», en La fête et l'écriture. Theatre de Cour, Cour-Théâtre en Espagne et en Italie, 1450-1530, Colloque International France- Espagne-Italie, Aix-en-Provence, 6-7-8 décembre 1985, Aix-en-Provence, Université de Provence, Centre Aixois de Recherches hispaniques (C.A.R.H.) et Centre Aixois de Recherches Italiennes (C.A.R.I.), 1987, pp. 33-49.

GERHARDT, Mia I.: Essai d'analyse littéraire de la pastorale dans les littératures italienne, espagnole et française, Utrech, Hes Publishers, 1975. Reimpr. de la tesis doctoral publicada en Assen, Van Gorcum, 1950.

HERMENEGILDO, Alfredo: «La neutralización del signo carnavalesco: el pastor del teatro primitivo castellano», en Texte, Kontexte Strukturen, Tübingen, Gunter Narr Verlag, 1987, pp. 283-295.

, Teatro de palabras: didascalias en la escena española del siglo XVI, Lleida, Edicions de la Universitat de Lleida, 2001.

HUIZINGA, Johann: El otoño de la Edad Media, trad. de José Gaos, Madrid, Revista de Occidente, 1930 [ed. Original: 1919].

LIHANI, John: El lenguaje de Lucas Fernández: estudio del dialecto sayagués, Bogotá, Instituto Caro y Cuervo, 1973.

MULRYNE, J. R. and Elizabeth GOLDRING (eds.): Court festivals of the European Renaissance: art, politics, and performance, Alershot, Ashgate, 2002.

- Helen WATANABE-O'Kelly and Margaret SHEWRING (eds.): Europa triumphans: court and civic festivals in early modern Europe, Aldershot, Ashgate, 2004, 2 vols.

OLEZA SIMÓ, Joan: "Hipótesis sobre la génesis de la comedia barroca», en Joan Oleza Simó (dir.) y Manuel V. Diago Moncholí (coord.), Teatros y prácticas escénicas. I. El quinientos valenciano, Valencia, Institució Alfons el Magnànim, 1984a, pp. 9-41. Editado primeramente en Cuadernos de Filología III (1-2), 1981, pp 153-223. 
, «La Valencia virreinal del Quinientos: una cultura señorial», en Joan Oleza Simó (dir.) y Manuel V. Diago Moncholí (coord.), Teatros y prácticas escénicas. I. El quinientos valenciano, Valencia, Institució Alfons el Magnànim, 1984b, pp. 61-75.

, «La tradición pastoril y la práctica escénica cortesana en Valencia (I): el universo de la égloga», en en Joan Oleza Simó (dir.) y Manuel V. Diago Moncholí (coord.), Teatros y prácticas escénicas. I. El quinientos valenciano, Valencia, Institució Alfons el Magnànim, 1984c V. Diago Moncholí (coord.), Valencia, Institució Alfons el Magnànim, 1984c, pp.189-217.

_, «La corte, el amor, el teatro y la guerra», Edad de Oro, V (1986), pp. 149- 182.

OVIDIO NASÓn, Publio: Arte de amar. Amores, ed. y trad. de Juan Antonio González Iglesias, Madrid, Cátedra, 1993.

PÉREZ PRIEGO, Miguel Ángel: «La égloga dramática», en Begoña López Bueno et al. (eds.): La égloga: VI Encuentro Internacional sobre Poesía del Siglo de Oro (Universidades de Sevilla y Córdoba, 20-23 de noviembre de 2000), Sevilla, Universidad de Sevilla, Servicio de Publicaciones, 2002, pp. 77-89.

Perugini, Carla (ed.): vid. Questión de amor, 1995.

PIERI, Marzia: «Dalla lirica alla festa: il caso dell'egloga nella Napoli Aragonese», en M. Chiabò y F. Doglio (eds.), Origini del Dramma Pastorale in Europa. Viterbo, 31 maggio-3 giugno, 1984, Viterbo, Centro Studi sul teatro Medioevale e Rinascimentale, 1985.

_, La scena boschereccia nel Rinascimento italiano, Padova, Liviana, 1983.

Question de amor, Valencia, Diego de Gumiel, 1513.

- Salamanca, Liom de Dei, 1528. Ed. digital en la BNE, <http://bdhrd.bne.es/viewer.vm?id=0000094741\&page $=1>$ (fecha de consulta: 26/ 09/ 2014).

, Venecia, Gabriel Giolito de Ferrariis, 1554. Ed. Digital de la BNE, <http://bdhrd.bne.es/viewer.vm?id=0000091534\&page=1 $>$ (fecha de consulta: 26/ 09/ 2014).

, Anvers, Philippo Nucio, 1576. Ed. digital en la BNE, <http://bdhrd.bne.es/viewer.vm?id=0000105156\&page $=1>($ fecha de consulta: 26/ 09/ 2014).

, ed. crítica de Carla Perugini, Universidad de Salamanca, Ediciones Universidad, 1995.

, Introduction, édition et notes de Françoise Vigier, Paris, Publications de la Sorbonne, Textes et documents $d u$ "Centre de recherche sur l'Espagne des $\mathrm{XVI}^{\mathrm{e}}$ et XVII ${ }^{\mathrm{e}}$ siècles» (CRES), 2006.

, ed. de Gregory Peter Andrachuk, Bristol, HiPLAM, 2006.

RECIO, Roxana: «Imitación, adaptación y asimilación: la transmisión de la poética petrarquista de I Trionfi》, en Revista de poética medieval, 18 (2007), pp.197210. 
, «Los Triunfos de Petrarca en los cancioneros: rastros de un género olvidado», en Marta Haro Cortés, Rafael Beltrán Llavador, José Luis Canet Vallés y Héctor H. Gassó (cords.), Estudios sobre el Cancionero general (Valencia, 1511): poesía, manuscrito e imprenta, Universitat de València, 2012.

RODADO RUIZ, Ana: «Poesía cortesana y teatro: textos semidramáticos en los cancioneros cuatrocentistas», en Felipe B. Pedraza y Rafael González Cañal, Los albores del teatro español. Actas de las XVII Jornadas de Teatro Clásico de Almagro, Julio 1994, Ciudad Real, Universidad de Castilla-La Mancha, 1995, pp.25-44.

RODRIGO MANCHO, Ricardo: «Notas en torno a la Farça a manera de tragedia», en Joan Oleza (dir.) y Manuel V. Diago Moncholí (coord.), Teatros y prácticas escénicas. I. El Quinientos valenciano, Valencia, Insitució Alfons El Magnànim-Diputació de València, 1984, pp. 219-241.

ROHLAND DE LANGHEHN, Regula: «Question de amor (1513), las tareas que asigna al lector y sus implicaciones, a partir de la «égloga» que incluye», en Antonio Vilanova (coord.), Actas del X Congreso de la Asociación Internacional de Hispanistas, Barcelona, 21-26 de agosto de 1989, Vol.1 (1992), pp. 533-542.

SALOMON, Noel: Lo villano en el teatro español del Siglo de Oro, Madrid, Castalia, 1985.

SAN JOSÉ LERA, Javier: «Teatro y texto en el primer Renacimiento español. Del teatro al manuscrito e impreso», Studia Aurea, 7 (2013), pp. 303-338.

SANNAZARO, Jacopo: Arcadia, Venecia, 1502/ Nápoles, Mayr, 1504. Ed. crítica de Francesco Tateo, Madrid, Cátedra (Letras Universales), 1993.

SÁNCHEZ HERNÁNDEZ, Sara: «Sayo, zurrón y cayado: vestuario y atrezo en el teatro de Juan del Encina», Dicenda. Cuadernos de Filología Hispánica (en prensa).

STERN, Daniels: Studies on the Sayagues in the early Spanish drama, Thesis (Ph.

D.),University of Pennsylvania, 1960.

SHERGOLD, Norman David: A History of Spanish Stage: from Medieval Times until the End of the Seventeenth Century, Oxford, Clarendon Press, 1967.

STRONG, Roy C.: Arte y poder: fiestas del Renacimiento, 1450-1650, Madrid, Alianza Editorial, 1988.

SUBIRÁ, José: La participación teatral en el antiguo teatro español, Barcelona, Diputación Provincial, 1930.

SURTZ, Ronald E.: The birth of a Theater: Dramatic convention in the Spanish Theater from Juan del Enzina to Lope de Vega, Madrid, 1979.

_, «El teatro en la Edad Media», en José María Díez Borque (dir.), Historia del teatro en España. I. Edad Media, Siglo XVI, Siglo XVII, Madrid, Taurus, 1990, pp.61-154.

TORRENTE, Álvaro: «La música en el teatro medieval y renacentista», en Javier Huerta Calvo (coord.), Historia del teatro español. 1. De la edad Media a los Siglo de Oro, Madrid, Gredos, 2003, pp. 269-302.

VIGIER, Françoise (ed.): vid. Question de amor, 2006. 
VICENTE, Gil: Tragicomedia de Don Duardos, ed. De Dámaso Alonso, Madrid, Centro Superior de Investigaciones Científicas, Instituto Antonio de Nebrija, 1942-, 2 vols.

VILlaVERDE, Fernando (ed.): La fiesta en la Europa de Carlos V: [exposición] Real Alcázar, Sevilla, 19 de septiembre-26 de noviembre 2000, Madrid: Sociedad Estatal para la Conmemoración de los Centenarios de Felipe II y Carlos V, 2000.

VIRGILIO MARÓN, Publio: Bucólicas, ed. bilingüe de Vicente Cristóbal, Madrid, Cátedra, 2000.

WATANABE-O'Kelly, Helen and Anne SimOn: Festivals and ceremonies: A Bibliography of Works Relating to Court, Civic and Religious Festivals in Europe 1500-1800, New York, Mansell, 2000. 